\title{
Mining the web for business intelligence: Homepage analysis in the internet era
}

Received (in revised form): 19th April, 2004

\section{Kin-nam Lau}

is currently an associate professor of marketing at The Chinese University of Hong Kong, Shatin, Hong Kong. His research interests include customer relationship management (CRM), data mining, management information systems (MIS) and marketing research. He has published in Journal of Management Information Systems, Journal of Marketing Research, Journal of Classification, Decision Science, European Journal of Operations Research and Journal of Database Marketing \& Customer Strategy Management. He obtained his PhD from Purdue University, USA.

\section{Kam-hon Lee}

is Professor of Marketing at The Chinese University of Hong Kong. His research areas include business negotiation, cross-cultural marketing, marketing ethics, social marketing and tourism marketing. He has published in the Journal of Marketing, Journal of Management, Journal of Business Ethics, European Journal of Marketing, International Marketing Review, Psychology and Health, The World Economy, Cornell HRA Quarterly and other refereed journals. He also serves on the editorial boards of various international and regional journals. He obtained his BCom and MCom at The Chinese University of Hong Kong and his PhD in marketing at Northwestern University in Evanston, Illinois, USA.

\section{Ying Ho}

is a PhD student in marketing at The Chinese University of Hong Kong. Her research focuses on tourism marketing. She has published in Cornell HRA Quarterly. She obtained her BBA at The Chinese University of Hong Kong and her MSc in international business at University of Manchester Institute of Science and Technology in Manchester, UK.

\section{Pong-yuen Lam}

is currently the Director of New Beverages for Coca Cola China Division. He started his marketing career with Procter \& Gamble Hong Kong in 1989 and was the Director of Marketing for McDonald's China in 1995-97. His research areas include MIS, text mining and operational research. He has published in the Journal of the Operational Research Society and Cornell HRA Quarterly. He received his BSc in computer science, MBA and PhD in marketing from The Chinese University of Hong Kong. He is also a Harvard alumnus after receiving the general manager executive education at Harvard Business School.

\section{Kin-nam Lau} Associate Professor of Marketing, Faculty of Business Administration, K. K. Leung Building, The Chinese University of Hong Kong, Satin, Hong Kong.

Tel: + 8522609 7766; Fax: + 8522603 5473; e-mail: knlau@baf.msmail. cuhk.edu.hk

\begin{abstract}
Information in websites provides good opportunities for marketers to understand and to acquire potential customers through the internet. The essence of web mining is to use powerful search engines to convert unorganised text information into customer intelligence stored in a database. In this paper, the authors construct a dictionary of 80,750 keywords/phrases to identify the portraits of 6,173 students from self-revealed information in their personal homepages. The authors summarise their empirical results and report the technological limitations and marketing challenges of web mining.
\end{abstract}

\section{INTRODUCTION}

Internet technology has undergone remarkable growth in recent years and has become an indispensable part of people's lives. As of March 2004, the worldwide internet population numbered
945 million. It is expected to achieve an annual growth rate of 16 per cent in 2005 and 2006. ${ }^{1}$ Most people will agree with the assertion that market modelling efforts over the next decade will reflect the internet's growing influence on 
consumer behaviour and marketing strategy. ${ }^{2}$ The internet is bringing about major changes in how businesses are conceived and managed, ushering in the era of e-business. ${ }^{3}$

Existing internet-related research focuses on how the development of the World Wide Web affects marketing decisions and consumer behaviours. For example, Prasad et al. analyse the relationship between pricing strategy and advertising levels for internet websites. ${ }^{4}$ Degeratu et al. compare how different store environments (online and traditional stores) can differentially affect consumer choices. ${ }^{5}$ Deleersnyder et al. quantify the impact of adding an internet channel on the long-term performance growth of a firm's established channels. ${ }^{6}$ On the consumer behaviour side, Dholakia et al. study the susceptibility of consumers to herding bias in digital auctions. ${ }^{7}$ Shankar et al. address the issue of customer satisfaction and loyalty in online and offline environments. ${ }^{8}$

Recent advances in internet technology provide market researchers with a continuous flow of timely and accurate business intelligence. For instance, knowledge about potential customers (eg gender, age, marital status, interests and hobbies) is available on personal homepages, which can be converted into consumer intelligence databases for marketing purposes. Discussions in newsgroups and online bulletin boards may serve as abundant sources of market intelligence (eg consumer preference, evaluation of existing products, customer complaints). Key firmographics (eg line of business, numbers of staff, year of establishment) can be extracted from company websites, which help managers better to understand business partners and competitors.

Traditionally, marketers have acquired customer information through market surveys. This process of information gathering, analysis and dissemination is labour intensive and time consuming. The internet offers an alternative channel for marketers to improve effectiveness and efficiency in their marketing research and customer acquisition efforts. In recent years, it has been noticeable that increasing numbers of the internet population now have their own personal webpages. This trend is expected to continue into the next decade because of the increasing ease of creating a homepage and people's increasing internet experience. More individuals are now setting up their own webpages to provide personal interests openly, and welcome other people to interact with them. Free web space can be easily and freely obtained from companies such as Yahoo, Netscape, AOL, etc. Software tools to create personal homepages are also getting more user-friendly. Companies such as Intel, Microsoft, Yahoo, etc are creating and promoting new uses of personal websites. For individuals, it is better to post family photos and/or videos of several megabytes in one's personal website for access by relatives and friends rather than e-mailing them. These personal websites contain enormous amounts of personal information in the form of text-based data, which can be converted into useful business intelligence for marketing purposes.

As an illustration, assume one is a tourist destination marketer who would like to understand potential customers for subsequent acquisition based on their life stage, socioeconomic and behavioural characteristics. Figure 1 is a personal webpage. This webpage identifies the owner as a well-educated, single female who likes music, drama, ball games, cycling and travelling. Given this understanding, tourist destination marketers may target the potential customer by offering service packages that match her interests. In this way, personal 


\section{About Gloria}

I am working as a merchandiser in a stationery company. $I$ am single. That's why I am still living with my parents and my brother. I got my Bachelor of Science degree in 2000. My major was mathematics.

I like cycling, playing piano, listening to music and playing ball games. During my school life, I also participated in many activities such as drama team. I like travelling too! I travelled to Thailand at the end of September 2001 with my family. I did lots of shopping and sightseeing there. It is really a wonderful place.

Thanks for visiting my page! Do e-mail me with any questions or suggestions for my webpage!

Figure 1: Personal webpage

websites provide marketers with a golden opportunity for capturing potential customers' self-revealed personal information and send them tailormade promotion packages.

\section{CONCEPT OF WEB MINING}

In principle, millions of webpage owners can be systematically categorised in a database structure. The task of converting textual information of a few webpage owners into a database could easily be carried out manually (ie by eye). However, due to the massive number of websites, a 'human eye' approach may demand thousands of website analysts working for a very long period of time. This would result in substantial cost, fatigue problems and difficulty in standardising different judgments by different analysts. Therefore, the process of webpage analysis has to be automated. This requires the researcher to develop a dictionary containing thousands of important keywords and/or phrases (eg terms underlined in Figure 1) and the use of a powerful engine to search each of these keywords in every webpage to identify its owner's characteristics. This process is referred to by the authors as 'web mining'. Web mining is the process of retrieving and converting text information on websites into an organised database containing key variables of interest for better understanding customers. It involves the use of text mining techniques which extract customer intelligence from unstructured or semi-structured text documents on personal websites. The ratio of structured to unstructured information currently stored electronically is estimated as 10 per cent structured to 90 per cent unstructured, and this trend is expected to continue. ${ }^{9}$ Through web mining, it is possible to make use of the personal information on the web to understand the demographic, behavioural and attitudinal characteristics of potential customers. Based on such understanding, marketers 
can offer tailormade service packages to individual customers.

The fundamental concept of web mining is actually not new to marketing researchers. Since the early 1950s, sociologists and psychologists have used content analysis to convert semi-structured qualitative information into well-structured information for statistical analysis. It had already gone through five methodological stages, namely: frequency analysis, valence analysis, intensity analysis, contingency analysis and computer analysis. In the late 1960s, researchers started to use computers to assist them in analysing text information. Today, numerous computer programs (eg CAIR, ATLAS/ti, Catpac, CDC, EZ-Text etc) are available for a more sophisticated content analysis. ${ }^{10}$

Since the 1980s, computer scientists have developed search engines for users to search the internet according to their self-selected keywords. Most of these engines are free and publicly available from ISP homepages (eg Yahoo, Netscape, etc). There are also marketing studies focusing on the use of search engines. Bradlow and Schmittlein evaluate the ability of six popular web search engines to locate webpages containing common marketing/ management phrases. ${ }^{11}$ Hoque and Lohse studied how the design of user interfaces in websites influences information search costs. ${ }^{12}$ This shows the promise of new marketing research methods which use the internet and websites. The present study continues this tradition and demonstrates a way of converting webpage information into a systematic marketing database.

Web searches via search engines (eg Yahoo, Netscape, MSN, etc) are extremely popular nowadays. The issue is, 'Are we satisfied with the results?' In most publicly available search engines, one is only allowed to use Boolean search terms (eg AND, OR, NOT) with a limited number of keywords, which is equivalent to asking each webpage owner a few questions. Thousands of webpages may satisfy the search criteria, yet the researcher still has to manually read through these pages to identify potential webpage owners. Since webpages satisfying a few keywords may not necessarily meet expectations, due to the 'context issue', such a process can be time consuming and may not be fruitful for marketing purposes. Unlike the current web search, web mining allows for search techniques beyond simple Boolean searches and accepts tens of thousands of keywords in the search process. The results of text search will be further analysed to identify key characteristics of each webpage owner.

The concepts of web mining and text mining are gaining increasing popularity nowadays. A number of powerful tools are currently available to analyse textual information in e-mails, customer surveys, corporate documents, medical records, patent databases etc (see Table 1). Industries such as financial services, insurance services, healthcare and consultancy have successfully applied text-mining techniques in their data management functions. Examples of businesses with successful applications are Principal Financial Group, ${ }^{13}$ Heritage Mutual Insurance, ${ }^{14}$ Hewitt Associates LLC, $^{15}$ Louisville Hospitals ${ }^{16}$ and Disease Research at the University of Pennsylvania. ${ }^{17}$ Users applaud the efficiency of these tools in managing huge amounts of text-based information. Since this concept has proven to be useful in a number of industries, the authors propose that marketers may use this technique to locate target customers, identify their needs and communicate with them at a relatively low cost.

In conclusion, web mining can be considered as the extension and 
Table 1: Text-mining software

\begin{tabular}{|c|c|c|}
\hline Product name & Vendor & URL \\
\hline SAS Text Mine & SAS & http://www.sas.com/technologies/analytics/datamining/textminer/ \\
\hline STATISTICA Text Miner & StatSoft & http://www.statsoftinc.com/textminer.html \\
\hline GoodNews & Robotics Institute & http://www-2.cs.cmu.edu/ softagents/text_miner.html \\
\hline SMART Text Miner & SMART Communications & http://www.smartny.com/miner.htm \\
\hline WordStat & Provalis Research & http://www.simstat.com/ \\
\hline ClearResearch & ClearResearch Corp. & http://www.clearforest.com/Products/Analytics/ClearResearch.asp \\
\hline Copernic Summarizer & Copernic Technologies & http://www.copernic.com/en/products/summarizer/ \\
\hline CATPAC & $\begin{array}{l}\text { Terra Research \& } \\
\text { Computing, Inc. }\end{array}$ & http://www.pbelisle.com/library/reviews/catpac6.htm \\
\hline $\begin{array}{l}\text { dtSearch Text } \\
\text { Retrival Engine }\end{array}$ & dtSearch Corp. & http://www.dtsearch.com/PLF_Features_2.html \\
\hline DataSet V & Intercon Systems & http://ds-dataset.com/DIMRS_Features.htm \\
\hline ISYS search solution & Odyssey Development & http://www.isysusa.com/products/index.html \\
\hline Klarity & Intology & http://www.intology.com.au/20products/ \\
\hline Kwalitan & Science Plus Group & http://www.scienceplus.nl/ \\
\hline Lextek Language Identifier & Lextek International & http://www.languageidentifier.com/ \\
\hline Leximancer & Leximancer & http://www.leximancer.com/overview.html \\
\hline Lextek & Lextek International & http://www.lextek.com/onix/ \\
\hline Matchpoint & Triplehop Technologies & http://www.triplehop.com/product_demos/matchpoint.html \\
\hline Monarch Pro & Datawatch Corporation & http://monarch.datawatch.com/ \\
\hline MindServer & Recommind Inc. & http://www.recommind.com/english/solutions/default.asp?url=Products \\
\hline Online Miner & Temis Group & http://www.temis-group.com/ \\
\hline TextQuest & Social Science Consulting & http://www.textquest.de/eindex.html \\
\hline Readware Information & Management & http://www.readware.com/prod_infoproc.asp \\
\hline Processor & Information Technology & \\
\hline VantagePoint & Search Technology & http://www.thevantagepoint.com/pages/whitesheet_1.html \\
\hline
\end{tabular}

Sources: http://www.google.com.hk

http://www.kdnuggets.com/software/text.html

improvement of current web search methods and traditional content analyses. Its ultimate goal is to integrate marketing research with database marketing in the internet era. Its objective can be stated as:

'To retrieve and convert unorganised text information from both personal and company websites into an organised database containing key marketing variables of interest to the researcher (eg demographics, socioeconomics, behaviour, interests etc) for better understanding of our customers'.

Web mining research in computer science focuses on the development of search algorithms and methods. ${ }^{18}$ To view it from a marketing information search perspective, five key stages are typically involved.

\section{Definition of research objectives and concepts}

It is crucial at the very beginning for marketers to identify their targeted population and the types of information they are looking for. Key aspects of personal information (labelled as 'concepts') are general demographics, stage of life cycle, hobbies/interests, wealth/purchasing power, etc. This stage 
is the same as the research problem definition stage in traditional market research.

\section{Web crawling (data collection)}

With research objectives set, web crawlers (ie sophisticated computer programs) are sent to a user-defined set of uniform resource locators (URLs) or a web space to collect information (eg text files, HTML files etc). Metadata collected from target homepages are stored in a database for text and data analyses. This stage is similar to the data collection stage in traditional market research.

\section{Dictionary construction and text search (questionnaire design and interview)}

As search engines and text mining tools can recognise keywords and phrases but cannot understand the concepts behind the text, it is necessary for researchers to construct a dictionary that acts as the knowledge base to associate keywords and phrases with specific concepts. The dictionary is then used to translate unorganised text on various global websites into meaningful figures and indexes, which provide significant meaning to marketers. With a comprehensive dictionary set, text mining tools act like interviewers to collect, analyse and store the personal information that can be mined from webpages. This stage is similar to the process of designing questionnaires and conducting interviews in traditional market research.

\section{Text analysis to identify key characteristics of customers (data analysis)}

At this stage, there are search results for each keyword. Since tens of thousands of keywords are used in the dictionary, an equal number of binary variables $(1=$ keyword matched and $0=$ keyword not matched) must be constructed. These variables are analysed, and the results are translated into rules to identify key characteristics for each webpage owner. This stage is equivalent to data analysis in traditional market research.

\section{Solving the non-response problem}

There are many reasons for non-responses (missing values). For example, different webpage owners may have different ways of expressing their behaviour. Therefore, it is difficult to construct a dictionary to capture all possible ways of expression. Even if the dictionary is almost perfect, webpage owners typically do not release all of their personal information to the public and this will result in a substantial number of non-responses to certain keywords. However, some missing information can be estimated through statistical techniques. Moreover, traditional survey research on a sample of webpage owners can be used as supplementary market information in tackling the non-response problem. This stage is equivalent to the handling of non-response problem in traditional survey research.

\section{Summary}

The intention of this paper is not to show that the web mining approach is ready and viable today. Instead, the authors argue that this approach has the potential to become a major trend in future marketing research. Their objective is to evaluate its feasibility through a real life study on approximately 6,000 student homepages using an existing text mining tool. The research focus is on the dictionary 
construction and text analysis process. Specific research questions are:

1 Is it possible to construct a concise dictionary so that keywords can be interpreted in the right context to identify key characteristics of webpage owners?

2 Is existing technology effective and efficient enough to analyse huge numbers of personal homepages?

3 What are the major concerns in future web mining applications?

In the following section, the authors first outline the design of their study and then explain the dictionary construction and text search processes.

\section{RESEARCH DESIGN OF FEASIBILITY STUDY}

To demonstrate the web mining process, envisage a group of marketers who are interested in studying the behavioural and demographic profiles of college students. The objective of the authors' web mining program is to build a comprehensive and well-structured information database for this market segment, which may facilitate better understanding of the specific needs and interests of individual student customers. Based on this understanding, marketers can locate a group of potential customers for a specific marketing programme and bring tailormade promotion packages to these individual customers.

Suppose students provide a company with their personal websites; marketers can then conduct a feasibility study on students from two major universities in the world. This study focuses on eight major attributes (called concepts) of a person's demographic profile. They are gender, year of study, major, marital status, sibling, quiet hobby, sports interest and travel interest. It is expected that the information will enable marketers to understand customer needs, and target their services at the customers whose needs most coincide with the service packages to be offered.

A number of powerful text-mining tools are available today for analysing e-mails, patent databases, etc. In this study, the authors used one of the well-known text mining products as the primary tool for text analysis — the IBM Intelligent Miner for Text. ${ }^{19}$ It is used for web crawling and text search. The researcher collected 7,941 HTML documents (personal homepages) from the target universities. As a result of preliminary screening, a total of 6,173 personal homepages were retained for analysis. The reasons for the removal of 1,768 homepages are described below.

\section{Non-English homepages}

The English dictionary constructed for this feasibility study cannot adequately cater for the text mining needs of personal homepages written in other languages.

\section{Non-personal homepages}

A number of webpages hosted on the universities' websites are webpages for courses, departments, assignments, etc, which do not contain personal information and thus are not the target subjects for this analysis.

\section{Miscellaneous problems}

There are other problems, such as homepages that cannot be loaded or read by the text search engine, pages containing no textual data, password-protected webpages and empty pages - mostly webpages under construction. In addition, webpages with 
more than one owner are not qualified as individual personal homepages and are thus excluded from this study.

\section{TEXT SEARCH AND DICTIONARY CONSTRUCTION}

\section{Text search}

As the text collection in this study is large, search indexes were pre-built to speed up the text search process. Major index types of the IBM Text Search Engine used in this study include the Linguistic Index and Ngram Index. The Linguistic Index applies the same linguistic processing to the search terms before searching while the Ngram Index involves no linguistic processing at all (see Figure 2).

Moreover, different types of query interface demonstrate varying degrees of search sophistication. Single-word query and multiple-term query can be enhanced by using section support, which specifies searching in specific sections of a structured HTML document eg in title, meta, and header fields (see Figure 3) or context-based query, which can be used to limit a phrase search within a sentence (see Figure 4).

\section{Dictionary construction}

The interpretation of keywords and/or phrases identified in homepages has to be context-based. For example, the word 'Mary' found in a homepage does not automatically imply that the homepage owner is a female. The complete sentence could be either 'This is my girlfriend Mary' or 'Mary's homepage'. Therefore, search results for different keywords/phrases have to be categorised into different levels; eg level one, level two and so on (in descending order of certainty). With search results on each keyword, the researcher will choose which result to use in interpreting the concept. Results at a lower certainty level will be used only when the results of a higher certainty level are unavailable. Within the same level of certainty, any conflicting result leads to a missing value. Dictionary construction for each concept is explained in Table 2.

\section{Gender}

This contains keywords and/or phrases indicating whether the homepage owner is a male or female. Search results of different certainty levels are:

1 Level one (most certain) - 1,816 male names and 1,648 female names ${ }^{20}$ are searched in the 'title', 'header' and 'meta' fields of HTML files. These sections of HTML files, especially the 'title' field, usually contain the name of the webpage owner. Therefore, names found in these sections are more likely to be in the right context, while names found in other parts of the document may be names of friends or relatives.

2 Level two (less certain) - 48,496 terms such as 'my name is John', 'call me Mary', etc are searched within all sections of an HTML document. A search term is matched only if the same search term appears in a document as a consecutive clause.

3 Level three (least certain) - other indicative phrases (eg my wife, my husband, etc) are searched in all sections of a document. Altogether there are 80 search terms. A search term is matched only if the same search term appears in a document as a consecutive clause.

\section{Year of study}

This concept includes keywords and phrases related to one's student status (ie 
Consider: Document contains: 'I also create web pages for myself'.

1. Using Linguistic Index

If search 'pages', then 'keyword matched'.

If search 'page', then 'keyword matched'.

2. Using Ngram Index

If search 'pages', then 'keyword matched'.

If search 'page', then 'keyword not matched'.

Figure 2: Differences between the Linguistic Index and Ngram Index

Consider: Document 1 contains: 'John's homepage' in title field Document 2 contains: 'John is good.' NOT in title field

Query requirement: Use section support for 'title'

Search result: If search 'John' in Document 1, then 'keyword matched'. If search 'John' in Document 2, then 'keyword not matched'.

Figure 3: Section support

Consider: 'I am married with one child. I like playing football'.

Query requirement: Use context-based query within a sentence.

Search result: If search 'like football', then 'phrase matched'.

If search 'with football', then 'phrase not matched'.

Figure 4: Context-based query

undergraduate or postgraduate). Keywords and phrases are searched within all sections of an HTML document. A search term is matched only if all words of the search term are found within the same sentence (but not necessarily as a consecutive clause). The number of search terms used for undergraduates and postgraduates are 83 and 82 respectively.

\section{Major}

Majors selected for this study are business, science and engineering, art, social sciences, medicine and law. For simplicity, the last four majors are grouped into a single category labelled 'others'. A 'double major' category is created taking into consideration the large number of students who have academic interests in more than one area. Names of majors and their associated courses are used as indications of one's concentration area/research interest. A level one result is obtained by searching 2,661 indicative phrases with majors such as 'my major is engineering'. This result level is most certain because, to a certain extent, the inclusion of indicative phrases (eg 'my concentration is', 'my major is') validates the interpretation of search terms in the right context. A level two result is obtained by searching 1,585 course names associated with the respective majors. A search term is 


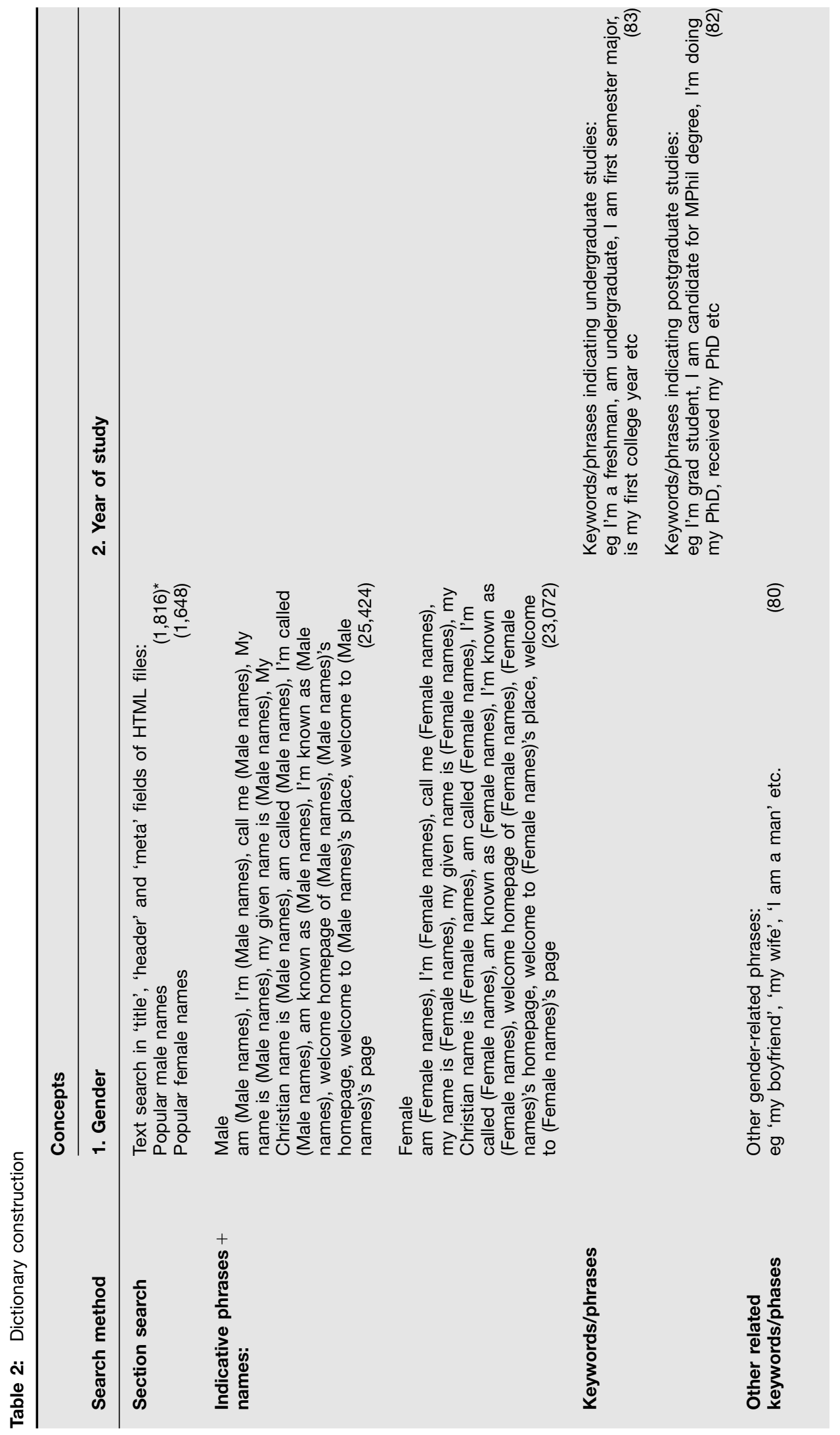




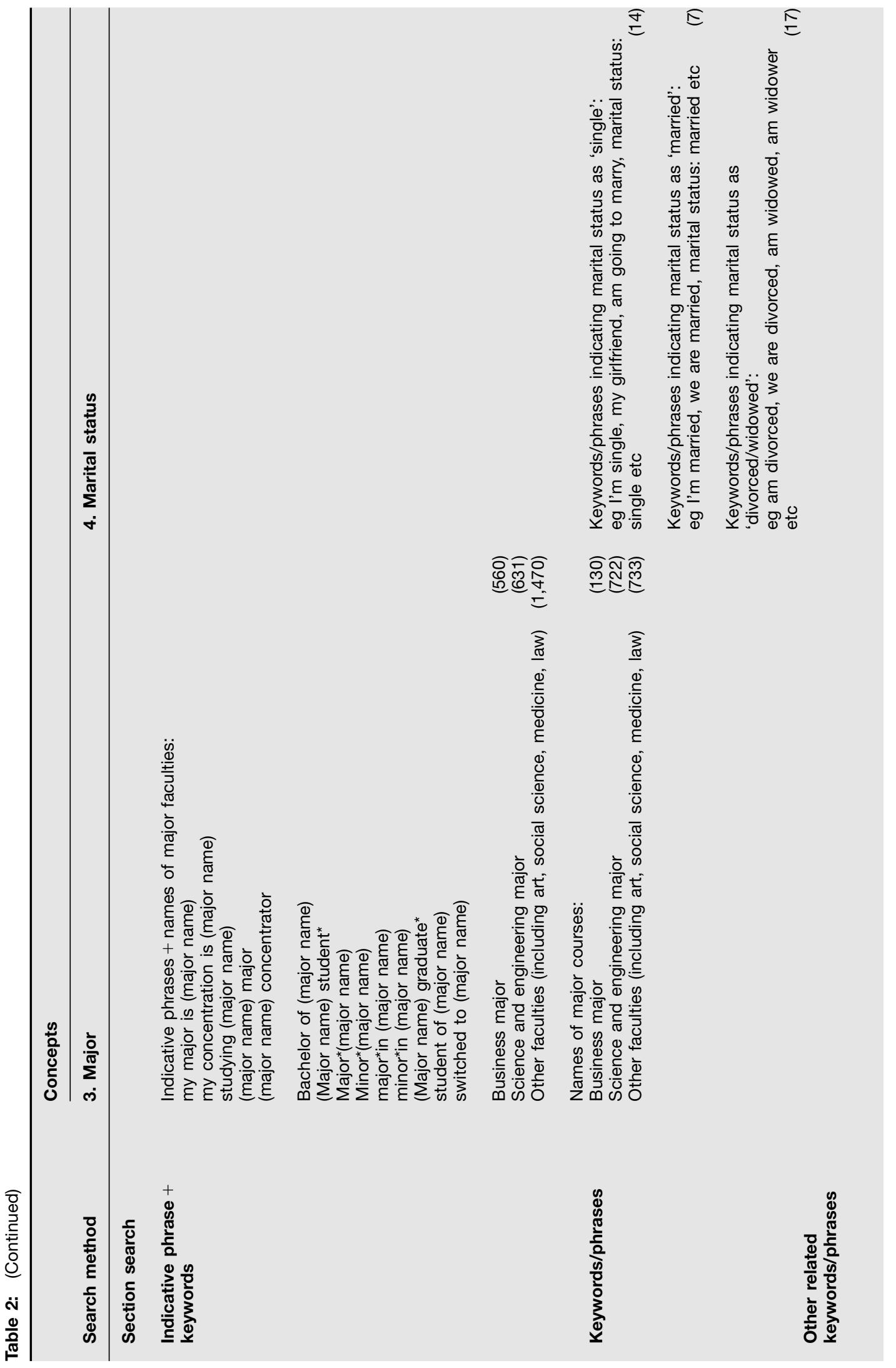




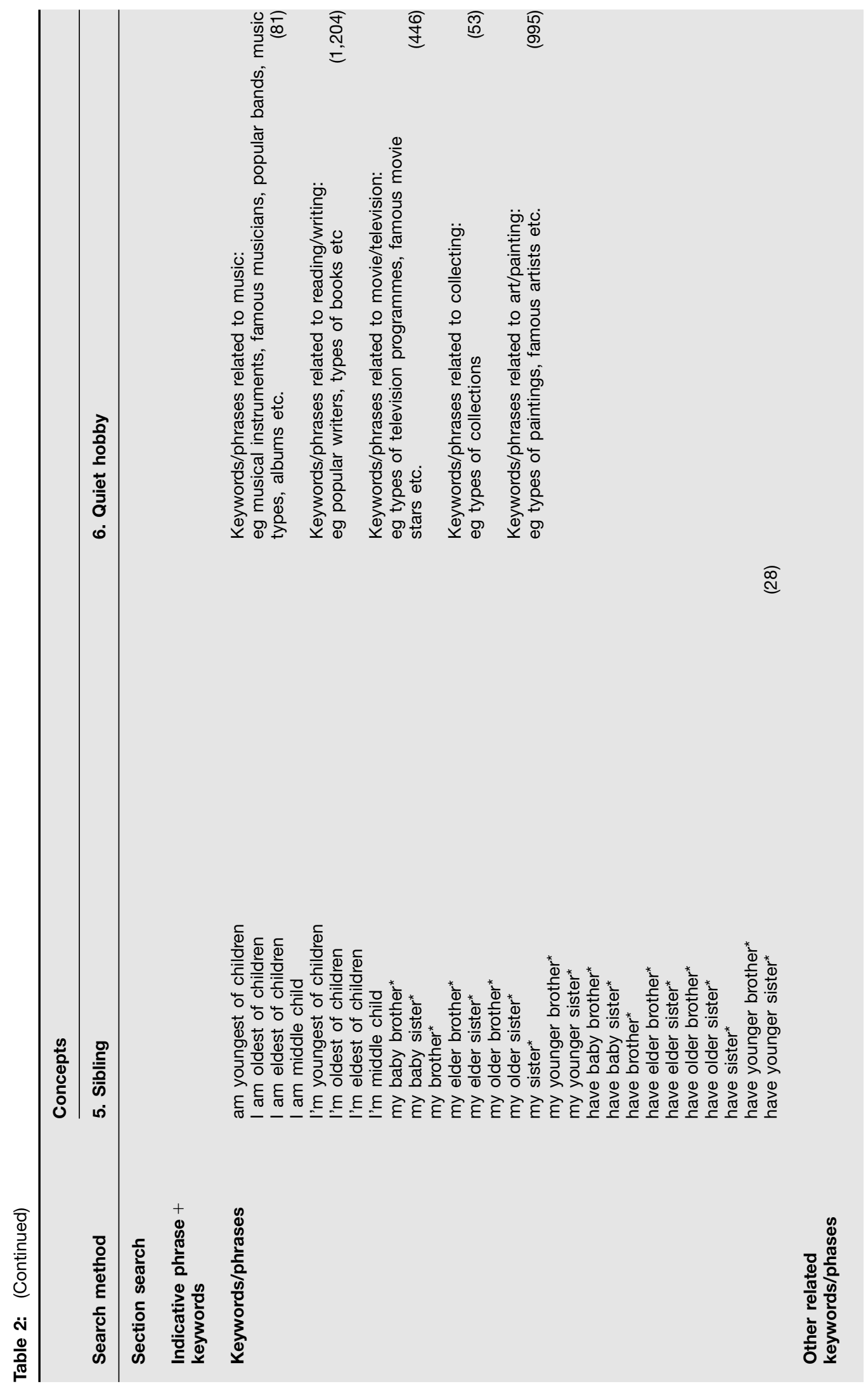




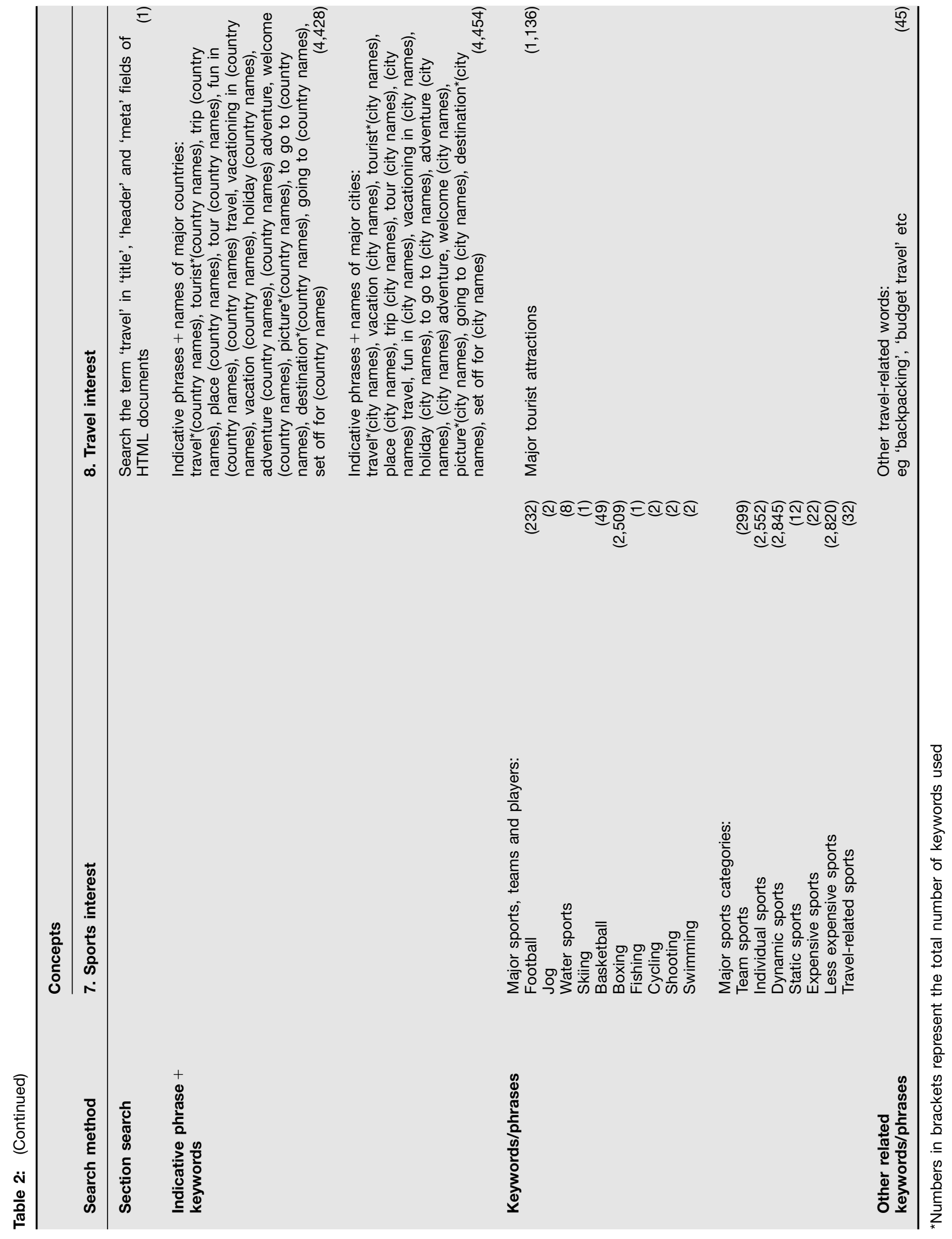


matched only if the same search term appears in the document as a consecutive clause. Majors and course names are compiled with reference to the academic curriculum of universities in the USA.

\section{Marital status}

This concept includes keywords and phrases indicating one's marital status ie single, married or others (eg divorced or widowed). Only one level of result is available, which is obtained by searching 38 phrases (eg 'I'm single', 'we are married', etc). A search term is matched only if the same search term appears in a document as a consecutive clause.

\section{Sibling}

This concept indicates whether the homepage owner has siblings or not. It consists of 28 search terms such as 'my brother', 'my sister', etc. A search term is matched only if all words of the search term are found within the same sentence (but not necessarily as a consecutive clause).

\section{Quiet hobby}

This concept explores the homepage owner's fondness for music, reading/writing, movie/television, collecting and arts/painting. Keywords for music contain musical instruments, famous musicians, popular bands, music types and music albums. The category of reading/writing contains names of writers and types of books. The category of movie/television consists of names of movie stars and types of television programme. Collecting specifies major types of collections eg coin collection, stamp collection, etc. Keywords related to arts/painting are names of artists and types of painting. The numbers of search terms for these five categories are 81, 1,204, 446,
53 and 995, respectively. A search term is matched only if the same search term appears in a document as a consecutive clause.

\section{Sports interest}

This concept identifies people's interests in sports, both by major sport types and sport categories. Major sport types selected are football, basketball, skiing, swimming etc. A total of 2,808 terms are searched for major sports types, which include names of sporting teams and players such as Houston Comets, Evander Holyfield, etc.

These individual sport types are further combined to form a number of sport categories such as team sports, individual sports, dynamic sports, static sports, expensive sports, less expensive sports and travel-related sports. Examples of each category are listed as follows:

1 Team sports — football, rugby, basketball, handball, hockey, softball, volleyball, etc.

2 Individual sports - auto racing, archery, bowling, boxing, bullfighting, diving, etc.

3 Dynamic sports - adventure racing, football, basketball, biathlon, etc.

4 Static sports - archery, boomerang, bowling, croquet, fishing, golf, etc.

5 Expensive sports - adventure racing, biathlon, boat racing, bullfighting, sky diving, etc.

6 Less expensive sports - football, basketball, table tennis, swimming, etc.

7 Travel-related sports - mountain biking, snow sports, scuba diving, snowboarding, etc.

These categories account for a total of 8,582 search terms. A search term is matched only if the same search term appears in a document as a consecutive clause. 


\section{Travel interest}

This concept explores one's potential interest in travel. Search results by different level of certainty are:

1 Level one - 1,136 names of worldwide tourist attractions such as 'Eiffel Tower', 'Golden Gate Bridge', etc are searched within all sections of an HTML document. Searching the names of tourist attractions is expected to produce the most accurate result for 'travel interest' because when people mention tourist attractions in their personal homepages, they are usually referring to the places they have visited, or the places they want to visit in the future.

2 Level two - the word 'travel' is searched in the 'title', 'header' and 'meta' fields of HTML files. It is observed that people who like travelling sometimes devote part of their homepages to travel-related articles, photos or hyperlinks. In these homepages, the term 'travel' is constantly found in the 'title', 'header' and 'meta' fields.

3 Level three - 8,882 indicative phrases plus names of countries/capital cities are searched within all sections of an HTML document. Examples are 'going to Asia', 'set off for Paris' etc.

4 Level four - other travel-related keywords and phrases (eg backpacking, budget travel, etc) are searched within all sections of an HTML document. As the identification of these terms does not guarantee that they are in the right context, this result level is the least certain among all four levels. The number of search terms for level four is 45 .

In summary, the results from text mining are largely determined by the accuracy and comprehensiveness of the pre-constructed dictionary. A lengthy dictionary with unnecessary questions would increase the search time, while an over-simplified one would result in a large number of missing values. Moreover, if the keywords or phrases included in the dictionary are not indicative enough, the search terms will be out-of-context and result in a low accuracy rate. Therefore, the dictionary should be concise and to-the-point, meaning the number of keywords and phrases identified for each concept should be kept to a minimum while, at the same time, be able to capture a maximum profile from a personal website. Once a high quality dictionary is secured, it becomes simple and cost effective for marketers to provide personalised services to potential customers on a routine basis. The dictionary constructed for this pilot study is available upon request.

\section{RESULTS OF TEXT SEARCH}

A total of 80,750 terms (keywords and phrases) was searched in each of the 6,173 homepages. The total search process took approximately one day. Compared with human eyes, the time efficiency was acceptable. Text search results are presented in Table 3. The most commonly identified concept is 'Gender' with missing value of about 35 per cent. It is observed that most students mention their names and/or include other gender indicative phrases such as 'my wife', 'my boyfriend', etc in their personal homepages. The percentage of missing values for other concepts such as 'year of study', 'major', 'quiet hobby', 'sports interest' and 'travel interest' ranges from 43 per cent to 67 per cent. The non-response problem is most serious for the 'sibling' and 'marital status' concepts, which have missing values of 87 per cent and 94 per cent respectively. This is understandable because college students are less likely to 
Table 3: Text search results

\begin{tabular}{|c|c|c|}
\hline Concept & Frequency count & Percentage \% \\
\hline \multicolumn{3}{|l|}{ 1. Gender } \\
\hline Male & 2,661 & 43.11 \\
\hline Female & 1,354 & 21.93 \\
\hline Missing & 2,158 & 34.96 \\
\hline \multicolumn{3}{|l|}{ 2. Year of study } \\
\hline Undergraduate & 1,122 & 18.18 \\
\hline Postgraduate & 1,040 & 16.85 \\
\hline Missing & 4,011 & 64.98 \\
\hline \multicolumn{3}{|l|}{ 3. Major } \\
\hline Business & 311 & 5.04 \\
\hline Science or engineering & 845 & 13.69 \\
\hline Others & 610 & 9.88 \\
\hline Double major & 567 & 9.19 \\
\hline Missing & 3,840 & 62.21 \\
\hline \multicolumn{3}{|l|}{ 4. Marital status } \\
\hline Single & 218 & 3.53 \\
\hline Married & 133 & 2.15 \\
\hline Missing & 5,822 & 94.31 \\
\hline \multicolumn{3}{|l|}{ 5. Sibling } \\
\hline With sibling & 815 & 13.20 \\
\hline Missing & 5,358 & 86.80 \\
\hline \multicolumn{3}{|l|}{ 6. Quiet hobby } \\
\hline Music & 1,129 & 18.29 \\
\hline Reading/writing & 361 & 5.85 \\
\hline Movie/television & 875 & 14.17 \\
\hline Collecting & 26 & 0.42 \\
\hline Art/painting & 562 & 9.10 \\
\hline Missing & 2,678 & 43.38 \\
\hline \multicolumn{3}{|l|}{ 7. Sports interest } \\
\hline Football & 752 & 12.18 \\
\hline Water sports & 185 & 3.00 \\
\hline Skiing & 192 & 3.11 \\
\hline Basketball & 430 & 6.97 \\
\hline Boxing & 80 & 1.30 \\
\hline Fishing & 171 & 2.77 \\
\hline Cycling & 51 & 0.83 \\
\hline Swimming & 323 & 5.23 \\
\hline Team sports & 1,357 & 21.98 \\
\hline Individual sports & 1,333 & 21.59 \\
\hline Dynamic sports & 1,872 & 30.33 \\
\hline Static sports & 575 & 9.31 \\
\hline Expensive sports & 833 & 13.49 \\
\hline Less expensive sports & 1,728 & 27.99 \\
\hline Travel-related sports & 769 & 12.46 \\
\hline Missing & 3,877 & 62.81 \\
\hline \multicolumn{3}{|l|}{ 8. Travel interest } \\
\hline Asia & 79 & 1.28 \\
\hline Europe & 153 & 2.48 \\
\hline Middle East & 24 & 0.39 \\
\hline Africa & 31 & 0.50 \\
\hline North America & 79 & 1.28 \\
\hline South America & 43 & 0.23 \\
\hline Oceania & 33 & 0.53 \\
\hline USA & 244 & 3.95 \\
\hline Missing & 4,157 & 67.34 \\
\hline
\end{tabular}

mention information about siblings and marital status on their personal webpages.

Table 4 gives a general overview of the number of concepts identified. The authors can successfully identify at least three concepts for 3,165 webpage owners, but all eight concepts are identified for only 16 out of a total of 6,173 subjects.

There are two key reasons for the large number of missing values. First, as website information is self-revealed, people have 
Table 4: Frequency for identified concepts

\begin{tabular}{ll}
\hline $\begin{array}{l}\text { Number of concepts } \\
\text { identified }\end{array}$ & Frequency count \\
\hline One concept only & 1,626 \\
Two concepts only & 1,382 \\
Three concepts only & 1,215 \\
Four concepts only & 897 \\
Five concepts only & 598 \\
Six concepts only & 331 \\
Seven concepts only & 108 \\
Eight concepts only & 16 \\
\hline
\end{tabular}

their own preferences concerning how much and what type of information to disclose to others. If people do not disclose such information on personal homepages, it is impossible for marketers to identify this information from the web.

Secondly, the constructed dictionary for this feasibility study could have been more exhaustive if there were more resources. For example, the current study includes names of popular music bands, pop singers, music albums and musical instruments in the 'music' category. In future, researchers might include more music-related terms, such as names of classical musicians, sound tracks, operas, etc, to further enhance the capability of the dictionary.

To sum up, the proportion of missing values is quite large for some concepts. Even so, the number of potential customers identified from web mining can still be large enough for profitable marketing if the target population is substantial. In addition, the objective of the web mining project is to establish a comprehensive database of customer information for one-to-one marketing. Every aspect of a person's demographic, attitudinal and behavioural data obtained may be useful to different marketers.

\section{ACCURACY OF TEXT SEARCH RESULT}

At this stage, the authors randomly selected 587 personal homepages (ie about 10 per cent of the total pool of personal homepages analysed) for two purposes:

1 To demonstrate the accuracy of dictionary construction and text analysis.

2 To use the sample result to formulate scoring rules for missing variables.

Accuracy results for individual concepts are presented in Table 5. The authors calculated the overall hit rate for each concept from:

overall hit rate $(\%)=($ correctly classified cases $\div$ total number of cases) $\times 100$.

In general, the text analysis results can be considered as reasonably accurate with six concepts attaining hit rates above 80 per cent. In particular, hit rates for 'year of study', 'marital status', 'sibling' and 'sports interest' (all above 85 per cent) are higher than other concepts. 'Gender', 'travel interest' and 'quiet hobby' have hit rates of 82 per cent, 81 per cent and 76 per cent respectively. The text search result for 'major' is less satisfactory, with a hit rate of 67 per cent because it has four prediction categories. There are three major factors that affect the hit rate context-based search, dictionary construction and multiple meanings for one word.

\section{Context-based search}

Correct interpretation of concepts requires keywords and phrases to be found in the right context as defined by the researcher. As discussed earlier under text search, query interfaces such as 'section support' and 'context-based query' are used to enhance the correct interpretation of search terms. However, 
Table 5: Accuracy of results

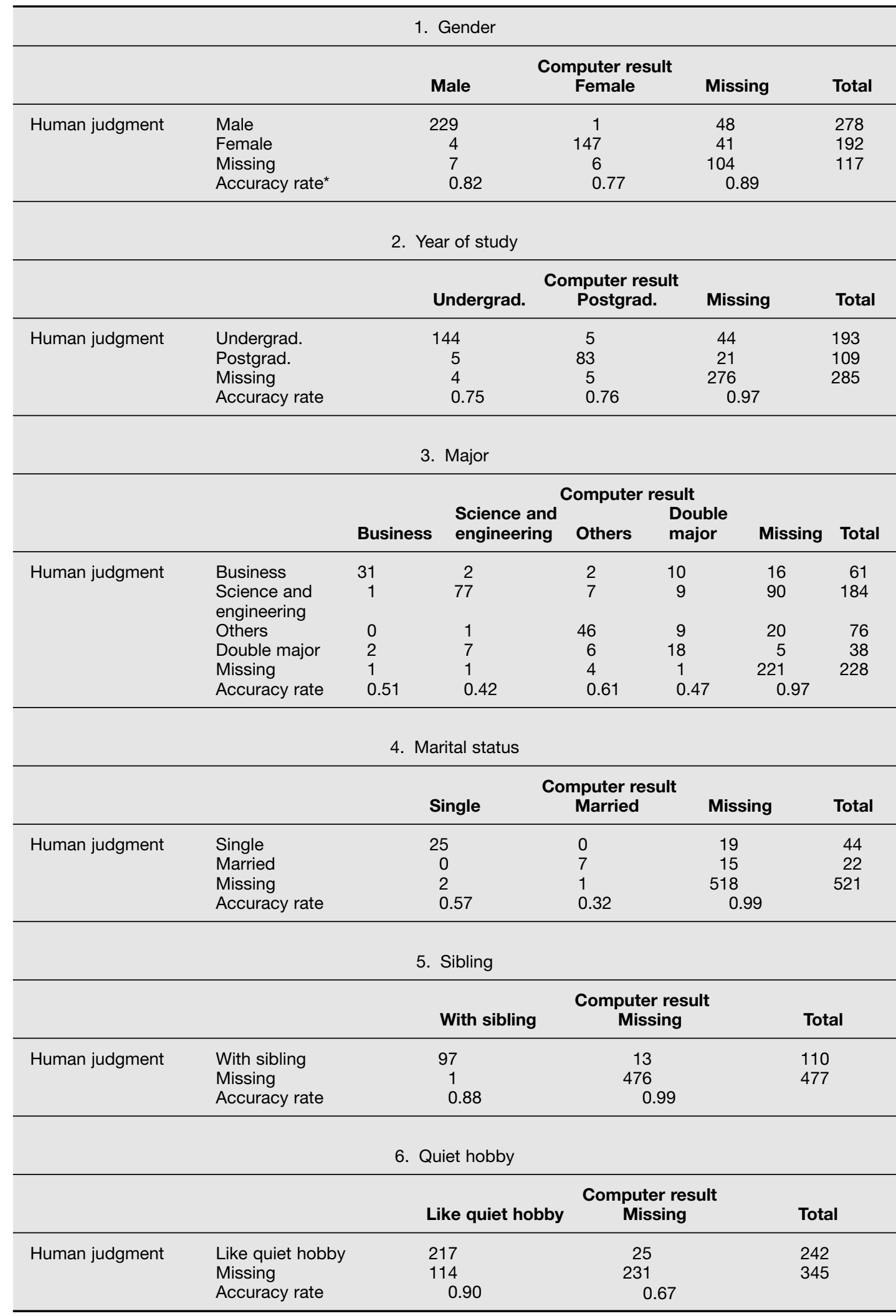


Table 5: (Continued)

\begin{tabular}{|c|c|c|c|c|}
\hline \multicolumn{5}{|c|}{ 7. Sports interest } \\
\hline & & \multicolumn{2}{|c|}{ Computer result } & \multirow[b]{2}{*}{ Total } \\
\hline & & Like sports & Missing & \\
\hline \multirow[t]{3}{*}{ Human judgment } & Like sports & 206 & 11 & 217 \\
\hline & Missing & 32 & 338 & 370 \\
\hline & Accuracy rate & 0.95 & 0.91 & \\
\hline \multicolumn{5}{|c|}{ 8. Travel interest } \\
\hline & & \multicolumn{2}{|c|}{ Computer result } & \\
\hline & & Like travel & Missing & Total \\
\hline \multirow[t]{3}{*}{ Human judgment } & Like travel & 81 & 14 & 95 \\
\hline & Missing & & 395 & 492 \\
\hline & Accuracy rate & 0.85 & 0.80 & \\
\hline
\end{tabular}

${ }^{*}$ Accuracy rate $(\%)=$ (true related cases $\div$ computer identified related cases $) \times 100$ per cent Example: accuracy rate for male $=(229 \div 278) \times 100$ per cent $=82$ per cent

current web mining tools have two technical limitations.

First, researchers cannot specify the word sequence of the same search term. For instance, the sentence 'Jane's boyfriend, my girlfriend and I love hiking' matches the search term 'my boyfriend'. In this case, even if, in fact, the webpage owner is a male, he will be wrongly identified as a female. The second technical issue is that the text analysis tool can only recognise $<\mathrm{p}>$ as an indication of sentence termination in HTML files. In reality, HTML files contain many format types such as table, list, etc. Thus, search results tend to be inaccurate, as the tool may not correctly identify the terminator of sentences.

\section{Dictionary construction}

The dictionary built for this study is not exhaustive in view of the huge number of terms and expressions that can be used to convey the same meaning. For example, for one's fondness of reading as a hobby, possible expressions might be 'reading is my life', 'reading is great fun', 'I like reading' and many other expressions.

\section{Multiple meanings for one word}

The possibility of multiple interpretations of a search term causes another problem for context-based search. The surface meaning of a term may be different from its latent meaning. For instance, the phrase 'my girl' may have different meanings; such as (1) my girlfriend, (2) my daughter and (3) a close female friend. It will be problematic, therefore, if a researcher considers only the first meaning (ie my girlfriend), and uses the term 'my girl' as an indication of male gender. This linguistic issue causes great difficulty in ascertaining the correct interpretation of search terms within the right context.

\section{SOLVING THE NON-RESPONSE PROBLEM}

When the value of a variable for a particular individual is missing after the text search, it can probably be inferred from the association relationship among the true variables observed in the random sample. The estimation procedure can be illustrated using gender as an example. From Table 5.1, 278 males and 192 females were directly 
observed and confirmed by eye (not by search engine) out of 587 students in the random sample. The authors constructed a training sample of 470 , which consists of all students with identified gender. Students whose gender cannot be identified by eye are excluded from this training sample. Let $Y_{i}=1$ if student $\mathrm{i}$ is a male, and $Y_{i}=0$ if student $\mathrm{i}$ is a female. Similarly, other variables (denoted by $X_{1}, \ldots, X_{n}$ ) can also be observed by eye for these 470 students in the training sample. These $X$ s are binary variables representing different categories (including missing) of all the concepts other than gender. Now treat $Y$ as the dependent variable and $\left(X_{1}, \ldots, X_{n}\right)$ as the independent variables in a stepwise logistic regression framework and apply it to the training sample to get:

$$
\begin{aligned}
\mathrm{V}= & 0.66+0.897{ }^{\star} \text { sport } 6-0.752^{\star} \\
& \text { hobby } 3-1.033^{\star} \text { sibling } \\
& -0.851^{\star} \text { major } 4 \\
\pi= & \exp (\mathrm{v}) /(1+\exp (\mathrm{v}))
\end{aligned}
$$

where sport6 $=1$ if the student loves 'less expensive sports' and 0 otherwise; hobby $3=1$ if the student enjoys 'movie or television and 0 otherwise; sibling $=1$ if the student has a sibling and 0 otherwise; major4 $=1$ if the student belongs to 'other major' and 0 otherwise; and $\pi$ is the probability that the student is a male.

Equations (1) and (2) suggest that if a student loves 'less expensive sports' and does not enjoy movie/television and has no sibling and does not belong to 'other major', this student has a higher chance of being a male. Then, they are used to generate scores (ie $\pi$ ) for those 2,158 students with missing gender after the text search process. Similarly, this technique is applied in order to generate scores for those who have missing values for 'year of study' and 'major'. The results are displayed in Table 6. As expected, most students with missing information on these variables are predicted to be male undergraduates majoring in science/engineering. The authors formulate the original association relationship among variables as a regression model for prediction purposes, but the scoring should not be interpreted as the causation results.

While the missing proportions for 'gender', 'year of study' and 'major' are relatively small (20-49 per cent) in the random sample, the missing proportions for other variables (re marital status, sibling, quiet hobby, sports interest and travel interest) are significantly higher (ie 59-89 per cent). The logistic regression can no longer be applicable to score customers with missing information on these variables, because there are no sufficient cases for discrimination on the dependent variable with respect to the independent variables. Consequently, scorings for all these variables cannot be internally generated from the web mining process. A traditional survey on a sample of web owners about the interests/activities they display as well as the interests/activities they do not display in their webpages would help to deduce the scores on such variables. For example, the score on travel interest $\pi_{t}$ can be approximated by the conditional probability of real interest in travel given the demographics of the webpage owner.

\section{CONCLUSION}

This paper presents an idea - the mining of websites by advanced internet technology and text mining techniques - for extracting meaningful information from personal websites for better understanding of customers. As stated in the research questions, the authors' most important concerns for web mining are:

(1) construction of a high quality 
Table 6: Scoring on missing variables

\begin{tabular}{|c|c|c|c|c|}
\hline Variables & & & Count & Percentage \\
\hline \multirow[t]{6}{*}{ Gender } & \multirow[t]{2}{*}{ Certain cases } & Male & 2,661 & $43.11 \%$ \\
\hline & & Female & 1,354 & $21.93 \%$ \\
\hline & \multirow[t]{4}{*}{ Uncertain cases } & Predicted score $^{\star}>0.75$ & 370 & $5.99 \%$ \\
\hline & & $0.5<$ predicted score $<0.75$ & 1,585 & $25.68 \%$ \\
\hline & & $0.25<$ predicted score $<0.50$ & 199 & $3.22 \%$ \\
\hline & & Predicted score $<0.25$ & 4 & $0.065 \%$ \\
\hline \multirow[t]{6}{*}{ Year of study } & \multirow[t]{2}{*}{ Certain cases } & Undergraduate & 1,122 & $18.18 \%$ \\
\hline & & Postgraduate & 1,040 & $16.85 \%$ \\
\hline & \multirow[t]{4}{*}{ Uncertain cases } & Predicted score $^{*}>0.75$ & 638 & $10.33 \%$ \\
\hline & & $0.5<$ predicted score $<0.75$ & 3,207 & $51.95 \%$ \\
\hline & & $0.25<$ predicted score $<0.50$ & 132 & $2.14 \%$ \\
\hline & & Predicted score $<0.25$ & 34 & $0.55 \%$ \\
\hline \multirow[t]{8}{*}{ Major } & \multirow[t]{4}{*}{ Certain cases } & Business & 311 & $5.04 \%$ \\
\hline & & Science or engineering & 845 & $13.69 \%$ \\
\hline & & Others & 610 & $9.88 \%$ \\
\hline & & Double major & 567 & $9.19 \%$ \\
\hline & \multirow[t]{4}{*}{ Uncertain cases } & Highest predicted score on: & & \\
\hline & & Business & 13 & $0.21 \%$ \\
\hline & & Science or engineering & 2,989 & $48.42 \%$ \\
\hline & & Others & 838 & $13.58 \%$ \\
\hline
\end{tabular}

Total: 6,173

*Predicted score is in a range of 0 to 1 where:

1 represents male, 0 represents female for gender;

1 represents undergraduate, 0 represents postgraduate for year of study.

dictionary; (2) capabilities of current web mining technology; and (3) other issues that may arise in web mining applications. The answers to these questions are summarised below.

The first concern is about the construction of a high quality dictionary capable of converting disorganised text in the web into a structured personal information database. Results of this feasibility study provide a promising start. The dictionary constructed can be considered to be fairly accurate in capturing and interpreting web information. It is also highly possible for researchers to revise the dictionary in the future so that more accurate text search results can be obtained in less computer time. However, given the self-revealed nature of web information, the dictionary can never be perfect, in the sense that marketers can never capture all customer data that are interesting to the marketers if these data are unavailable on the web.
Any inadequacies in the dictionary would result in missing values, which could only be partially resolved with statistical techniques and supplementary information obtained from traditional market survey research.

Regarding technical capability, the results of the feasibility study show that current web mining tools are capable of processing a large number of homepages (ie 6,173 HTML files) and attaining reasonably satisfactory text mining results. However, limitations still exist in the text mining tools, which need further improvement. In addition, current crawler technology is not capable of accessing web information stored in databases. Unless researchers know how to access a particular database, the data stored therein will become invisible because search engines cannot access dynamic databases. There is a need to develop a more advanced crawler technology.

There are also other important issues 
that deserve researchers' and practitioners' attention in future web mining applications and these are discussed below.

\section{Data availability and accuracy}

Data availability is an important issue that deserves practitioners' attention in future web-mining applications. To the best of the authors' knowledge, there are no commonly-agreed data about the current number and growth rate of personal homepages. As the construction of personal homepages is only in its early stage of development, the current number of personal homepage owners is rather low. However, current users are innovators who represent only a small proportion of the total population. When more webpage owners broadcast their website addresses to friends/relatives, the new idea and the usefulness of publishing one's personal homepage will permeate society and increase the number of adopters. It is possible to predict the number of personal webpages by calculating it as a simple multiple of (1) the total internet population; and (2) the proportion of internet users creating their own personal webpages. Even if the proportion of internet users creating their own personal webpages is assumed to remain the same as the current proportion, there will be more personal webpages as the internet population grows substantially. ${ }^{21}$ As more consumers display personal information on their personal webpages, it will be profitable for marketers to utilise the readily-available information on the web to understand their customers.

Marketers may also be concerned about data accuracy. As information obtained from both personal websites and traditional market surveys are self-revealed in nature, data accuracy in the web mining approach should be at least comparable to that of the traditional survey approach. Nonetheless, data integrity problems may also arise when a person has a number of homepages, of which some contain outdated or inaccurate information. Inaccurate data may cause noise in marketing prediction.

\section{Privacy issues}

The possible invasion of individual privacy and misuse of customer information could seriously impede marketing progress on the web. ${ }^{22}$ Analysis of personal information on individual websites and the subsequent use of this information for marketing purposes may cause ethical concerns. However, if customers provide their website addresses to marketers voluntarily, there would be no risk of invading individual privacy.

To sum up, web mining has significant marketing implications. It presents an alternative to traditional marketing research which gains an understanding of the target population through statistical inference from a representative sample. Even though the target population is very large, the size of the survey (qualitative or quantitative) is still relatively small, due to cost and time constraints. By comparison, the web-mining approach studies all accessible web information (ie the population) instead of just the sample. The web-mining approach will study each individual homepage, of which there could be thousands of millions in the world. The marketing value of the web-mining technique increases with the increasing number of customers who have their own webpage. It is profitable for marketers to make use of these readily available information sources better to understand their customers.

The current study of personal homepages of college students is only one of the many business applications of web-mining technology. Marketers may use web-mining techniques to acquire 
customer intelligence from personal homepages and newsgroups and to obtain competitor intelligence from company websites. In the meantime, it is appropriate to acknowledge the technical difficulty, as well as the complexity and uncertainty, of future technological developments. In addition, web mining technology alone cannot facilitate the development of a comprehensive customer database. It has to be supplemented by traditional survey research and statistical techniques to handle the non-response problem. Furthermore, the success of this marketing approach depends heavily on the public acceptance of personal websites. These concerns pose a certain degree of uncertainty on its future advancement.

The aim of this paper is to study the feasibility of web mining applications rather than to report a successful story. The results are, by no means, indications of its future success. There is room to enhance this new approach for better accuracy and efficiency. It is the authors' hope that this paper will generate interest and discussion among academics and practitioners in this new area of marketing research.

\section{Acknowledgment}

The authors thank IBM for their technical support in this project.

\section{References}

1 http://www.clickz.com/stats/big picture/geographics/article.php/151151.

2 Mahajan, V. and Venkatesh, R. (2000) 'Marketing modeling for e-business', International Journal of Research in Marketing, Vol. 17, No. 2-3, pp. 215-225.

3 Lilien, G. L. and Rangaswamy, A. (2000) 'Modeled to bits: Decision models for the digital, networked economy', International Journal of Research in Marketing, Vol. 17, No. 2-3, pp. 227-235.

4 Prasad, A., Mahajan, V. and Bronnenberg, B. (2003) 'Advertising versus pay-per-view in electronic media', International Journal of Research in Marketing, Vol. 20, No. 1, pp. 13-30.
5 Degeratu, A. M., Rangaswamy, A. and Wu, J. (2000) 'Consumer choice behavior in online and traditional supermarkets: The effects of brand name, price, and other search attributes', International Journal of Research in Marketing, Vol. 17, No. 1, pp. 55-78.

6 Deleersnyder, B., Geyskens, I., Gielens, K. and Dekimpe, M. G. (2002) 'How cannibalistic is the internet channel? A study of the newspaper industry in the United Kingdom and the Netherlands', International Journal of Research in Marketing, Vol. 19, No. 4, pp. 337-348.

7 Dholakia, U. M., Basuroy, S. and Soltysinski, K. (2002) 'Auction or agent (or both)? A study of moderators of the herding bias in digital auctions', International Journal of Research in Marketing, Vol. 19, No. 2, pp. 115-130.

8 Shankar, V., Smith, A. K. and Rangaswamy, A. (2003) 'Customer satisfaction and loyalty in online and offline environments', International Journal of Research in Marketing, Vol. 20, No. 2, pp. 153-175.

9 Zorn, P., Emanoil, M., Marshall, L. and Panek, M. (1999) 'Mining meets the web', Online, Vol. 23, No. 5, pp. 16-28.

10 Popping, R. (2000) 'Computer-assisted Text Analysis’, Sage Publications, London.

11 Bradlow, E. C. and Schmittlein, D. C. (2000) 'The little engines that could: Modeling the performance of world wide web search engines', Marketing Science, Vol. 19, No. 1, pp. 43-62.

12 Hoque, A. Y. and Lohse, G. L. (1999) 'An information search cost perspective for designing interfaces for electronic commerce', Journal of Marketing Research, Vol. 36, No. 3, pp. 387-394.

13 http:www-3.ibm.com/software/success/cssdb.nsf/ csp/navo-4vpvek.

14 http://www.kmworld.com/resources/ featurearticles/index.cfm?action $=$ readfeature $\&$ feature_id=130.

15 http://www-3.ibm.com/software/success/ cssdb.nsf/CS/NAVO-4D8PWL?Open Document $\&$ Site $=$ software.

16 http://www.sas.com/success/louisville.html.

17 http://www.spss.com/press/template_view.cfm? PR_ID $=571$.

18 Chang, G., Marcus J. H., McHugh, J. A. M. and Wang, J. T. L. (2001) 'Mining the World Wide Web: An Information Search Approach', Kluwer Academic Publishers, Boston, MA.

19 http://www-3.ibm.com/software/data/ iminer/fortext/.

20 Withycombe, E. G. (1977) 'The Oxford Dictionary of English Christian Names', Clarendon, New York, NY.

21 Lau, K. N., Lee, K. H., Lam, P. Y. and Ho, Y. (2001) 'Web-site marketing for the tourism industry: A rejoinder', Cornell Hotel and Restaurant Administration Quarterly, Vol. 42, No. 6, pp. 66-67.

22 Krauss, M. (2000) 'Get a handle on the privacy wild card', Marketing News, Vol. 34, No. 5, p. 12. 